\title{
Evaluating the Knowledge of HIV Transmission and Prevention of Mother to Child Transmission (PMTCT) of HIV among HIV-Positive Mothers Accessing Care in Military Hospital in Lagos, Nigeria
}

\author{
Nkechinyere Elizabeth Harrison1,2*, Kenneth Ejiofor Oruka1, Uzoamaka Concilia Agbaim1, \\ Olutunde Ademola Adegbite ${ }^{1}$, Nathan Anelechi Elvis Okeji ${ }^{3}$ \\ ${ }^{1}$ Centre for Infectious Disease Clinic, 68 Nigerian Army Reference Hospital Yaba, Lagos, Nigeria \\ ${ }^{2}$ Department of Medicine, 68 Nigerian Army Reference Hospital Yaba, Lagos, Nigeria \\ ${ }^{3}$ Ministry of Defence, Health Implementation Programme, Abuja, Nigeria \\ Email: ^nke1207@yahoo.com
}

How to cite this paper: Harrison, N.E., Oruka, K.E., Agbaim, U.C., Adegbite, O.A. and Okeji, N.A.E. (2021) Evaluating the Knowledge of HIV Transmission and Prevention of Mother to Child Transmission (PMTCT) of HIV among HIV-Positive Mothers Accessing Care in Military Hospital in Lagos, Nigeria. World Journal of AIDS, 11, 25-40.

https://doi.org/10.4236/wja.2021.111003

Received: January 5, 2021

Accepted: March 28, 2021

Published: March 31, 2021

Copyright $\odot 2021$ by author(s) and Scientific Research Publishing Inc. This work is licensed under the Creative Commons Attribution-NonCommercial International License (CC BY-NC 4.0). http://creativecommons.org/licenses/by-nc/4.0/ (c) (i) (8) Open Access

\begin{abstract}
Introduction: The prevention of mother-to-child transmission (PMTCT) plays a major role in limiting the number of children being infected by HIV. There is dearth of studies that explored the knowledge of HIV transmission and PMTCT among women living with HIV. Methods: This was a cross- sectional, descriptive study of HIV-positive mothers receiving medical care at the adult antiretroviral therapy (ART) clinic, 68 Nigeria Army Reference Hospital Yaba. A pre-tested structured questionnaire was used to collect information from the subjects concerning their socio-demographic, knowledge of HIV transmission and mother-to-child transmission of HIV and preventive measures. SPSS v23 was used for data analysis. Results: Out of the 374 participants, $282(75.4 \%)$ were aware that HIV can be transmitted to an unborn baby from the positive mother. Of these, 240 (85.1\%) were well-informed that increase mother's viral load can increase the chances of mother-to-child transmission. 268 (95\%) understood that giving of antiretroviral drugs during and after pregnancy can lower transmission risk, while 254 (90.1\%) saw the use of breast milk substitutes as another prevention strategy. There was statistically significant association between the respondents' knowledge of PMTCT and their husbands'/partners' awareness of their HIV status. Conclusion: In conclusion, our study demonstrated a good knowledge of HIV transmission, MTCT and PMTCT among women who were receiving ART in our centre. Disclosure is a significant factor found to be associated
\end{abstract}


with PMTCT knowledge. More studies can also explore if the observations in our study with women living with HIV will be comparable in similar population in different settings.

\section{Keywords}

Prevention of Mother to Child Transmission of HIV, HIV Positive, Mothers, Nigeria

\section{Introduction}

Mother-to-child transmission (MTCT) of human immune deficiency virus (HIV) infection is the transmission of the virus from an HIV-infected mother to her child during pregnancy, labour, delivery or breastfeeding [1] [2]. The global human immunodeficiency virus (HIV) epidemic continues to expand, with an estimated five million people becoming infected each year. Over the decades, the epidemic once dominated by infected males has become progressively feminized, with over half of adults living with HIV being women [3]. In sub-Saharan Africa, where about two-thirds of the global disease burden resides, $57 \%$ of adults living with HIV are women. As more women contract the virus, the number of children infected from their mothers has been growing. Every day there are nearly 1800 new HIV infections in children under 15 years of age, more than $90 \%$ occurring in the developing world. Most (about 90\%) of these infections are associated with MTCT. In addition, everyday 1400 children under 15 years of age die of an HIV-related illness [4]. Thus, prevention of MTCT of an $\mathrm{HIV}$ infection is a politically and scientifically accepted approach to reduce the impact of HIV, especially on children [5]. The prevention of MTCT plays a major role in limiting the number of children being infected by HIV.

Without treatment, the chance of transmitting HIV to a baby by an HIV positive mother could be up to $45 \%$. However, antiretroviral treatment (ART) and other interventions can reduce this risk to below 5\% [6]. PMTCT programmes provide a range of services to women and infants. These include preventing HIV infections among women of reproductive age (15 - 49 years), preventing unwanted pregnancies among women living with HIV, and providing women living with HIV with lifelong ART to maintain their health and prevent transmission during pregnancy, labour and breastfeeding. PMTCT programmes also support safe childbirth practices and appropriate infant feeding, as well as providing infants exposed to HIV with virological testing after birth and during the breastfeeding period, ART for prevention and effective treatment. Around 1.4 million HIV infections among children were prevented between 2010 and 2018 due to the implementation of PMTCT services [7]. In 2017, 80\% of pregnant women living with HIV were receiving ART, a significant increase from 2010 levels when only 51\% had access [7]. Despite this significant progress, 740,000 women of reproductive age became HIV positive in 2016. Around $73 \%$ of these 
women live in just 23 countries, the vast majority of which are in sub-Saharan Africa, and are classified as high-priority for PMTCT by UNAIDS [8].

In 2017, just over half (52\%) of the 1.8 million children living with HIV were receiving ART. Among those without access to effective treatment, 110,000 died due to AIDS-related illnesses [7]. In addition, roughly half the 180,000 children newly infected with HIV were infected during breastfeeding in 2017 [8]. There are particular challenges in maintaining women living with HIV in care and on effective ART throughout the breastfeeding period, as well as reducing, detecting and managing new infections occurring among women while they are pregnant or breastfeeding. As a result, in some countries more infant infections are now occurring during the postnatal period rather than pregnancy or labour [8].

In 2016, UNAIDS with PEPFAR among others launched Start Free, Stay Free, AIDS Free-a framework calling for a worldwide sprint towards "super fast-track targets" to end AIDS among children, adolescents and young women by 2020. Targets relating to PMTCT include reducing the number of new HIV infections among children to fewer than 40,000 by 2018 and fewer than 20,000 by 2020 . There is also a commitment to ensure that $95 \%$ of pregnant women living with HIV are receiving lifelong HIV treatment by 2018 [9].

A number of studies have identified the link between knowledge of HIV, MTCT and PMTCT and uptake of PMTCT services. For example, research from Togo reported a 92\% HIV testing uptake among participants where: $77 \%$ of pregnant women agreed that unprotected sex increased the risk of HIV transmission to their child $61 \%$ recognised that the risk of HIV transmission to their child was higher for mixed breastfeeding than for exclusive breastfeeding [10]. Another study of over 500 pregnant and postnatal women in Botswana with high PMTCT knowledge found that $95 \%$ of participants believed that pregnant women should be tested for HIV [11]. Conversely, other studies have associated high levels of HIV, MTCT and PMTCT knowledge with lower acceptability of PMTCT. A study from south west Nigeria revealed that while $99.8 \%$ of pregnant women were aware of HIV and had very high knowledge of MTCT (92\%) and PMTCT (91\%), a significant proportion (71\%) had negative views towards PMTCT due to factors such as stigma and discrimination [12]. Knowledge of HIV status is vital in order to enable pregnant women access appropriate treatment and care for themselves and their unborn infants [13]. Moses et al. (2009) working in North Eastern Nigeria showed a high level of knowledge of HIV transmission and prevention but only $42 \%$ of them had accurate knowledge of preventive intervention to babies [14]. Similarly, one study done in a referral Hospital in Ethiopia showed that less than half (48.3\%) of the respondents knew that antiretroviral drugs given for seropositive pregnant mothers could reduce the risk of transmission [15].

Some studies have identified barriers to PMTCT services in Nigeria. Many women do not have access to HIV test during pregnancy because of inadequate voluntary counselling and testing centres, and prevalence of stigma, absence of family support, and poor attitudes of healthcare workers [16] [17]. Although 
some progress has been reported in scaling up access to PMTCT services, more effort is still needed as Nigeria remains one of the 22 focus countries of the global plan to eliminate MTCT [18].

To our understanding, there is dearth of studies that explored the knowledge of HIV transmission and PMTCT among women living with HIV. Hence, this cross-sectional survey is designed to assess both the knowledge of HIV transmission and PMTCT among HIV positive mothers receiving ART services at $68 \mathrm{Ni}$ gerian Army Reference Hospital, Yaba Lagos Nigeria.

\section{Methods}

\subsection{Study Design}

This study was a quantitative, non-experimental questionnaire-based descriptive survey which applied cross-sectional approach in its design.

\subsection{Study Location}

The study was carried out at 68 Nigerian Army Reference Hospital Yaba (68NARHY), Lagos. This health facility is a 500-bed capacity tertiary military hospital which provides services to both the military and civilians and sees approximately six thousand in-and-out patients per month. It is a referral center for the Nigerian service men and civilians and is located at the hearth of Yaba Local Council Development Area of Lagos State. This zone lies in South-Western Nigeria, in the Gulf of Guinea, west of the Niger River delta. The area is situated on the longitude $3^{\circ} 24^{\prime} \mathrm{E}$ and latitude $6^{\circ} 27^{\prime} \mathrm{N}$, with monthly rainfall fluctuating markedly from the trough of $35 \mathrm{~mm}$ (1.5 inches) in January to the peak of $300 \mathrm{~mm}$ (12 inches) in July. The hospital operates daily adult HIV clinic at its Centre for Infectious Disease Clinic (CID) with average daily clinic attendance of 100 clients.

\subsection{Study Population}

This comprised of all HIV-positive mothers receiving medical care at the adult ART clinic, 68 Nigeria Army Reference Hospital Yaba. All mothers who provided oral informed consent to participate in the study were considered for recruitment.

\subsection{Sample Size Determination}

Cochrane formula for sample size estimation from infinite population in descriptive survey was applied to arrive at 384 participants) as follows:

$$
n=\frac{z^{2} p q}{e^{2}} \quad(\text { Cochrane 1963: 75) }
$$

where the meaning of the letters is as shown below:

$$
n=\text { sample size. }
$$

$p=50 \%$ or 0.5 (Assumed prevalence or proportion of event of interest, i.e. knowledge of HIV and PMTCT among positive mothers). 
$q=1-p$ (which is equal to 0.5 ).

$\mathrm{e}=5 \%$ 0r 0.05 (level of precision).

$Z=$ critical value of $Z$ at $95 \%$ confidence interval (which is equal to 1.96 according to $z$-table).

\subsection{Data Collection}

A pre-tested structured questionnaire $(r=0.72)$ was used to collect information from the subjects concerning their socio-demographic characteristics, knowledge of HIV transmission and mother-to-child transmission of HIV and preventive measures. To ensure accurate and consistent data, three research assistants were trained by the researchers on the content of questionnaire, data collection procedures and sampling methods. These were conveniently distributed to the respondents who filled in the responses by themselves but were supervised and/or assisted by the research assistants while they filled them in order to ensure accuracy and consistency of responses. Questionnaire distribution and collection lasted for two months, from April 15 to May 19, 2018 at which the estimated sample size has been reached.

\subsection{Statistical Analyses}

Questionnaires were sorted and checked for completeness, after which it was coded and entered into Excel spread sheet from where it was transferred to Statistical Package for Social Studies for windows (SPSS v23. Chicago Inc.) where data analysis was completed. The key outcomes for the study were the respondents' knowledge of HIV transmission and awareness of PMTCT programs as defined by their ability to identify factors potentiating maternal-to-child transmission of HIV and its preventive measures. Secondary outcomes were socio-demographic factors associated with the desired outcome measures. All questions were coded to assign one point to every correct response in the relevant sections. Question items that had more than one option were recoded to also allocate 1 point to the correct response(s) while all incorrect responses were aggregated and scored as zero. The final scores were summed up to form two indices: HIV knowledge, (score range 0 - 15) and PMTCT knowledge (score range 0 - 23). A cut-off was set in the sum of scores and categorized as poor HIV transmission knowledge (score $<10$ points) or high knowledge (score $\geq 10$ points); and poor (score $<16$ points) or good (score $\geq 16$ points) PMTCT knowledge. Normality of distribution of the resulting continuous dependent variables was assessed with Kolmogorov-Smirnov test. The results indicate that the HIV knowledge scores did not follow a normal distribution, $\mathrm{D}(374)=0.211, p<$ 0.001 ; likewise, PMTCT knowledge, D (374) $=0.082, p<0.001$, hence nonparametric techniques were employed throughout the analyses. The independent influence of the participants' socio-demographic variables on PMTCT knowledge was established. For continuous independent variables, spearman's rho correlation was used to assess for the relationship with the outcome variables, Mann- 
Whitney $U$ test was used for categorical independent variables with only two groups, whereas assessment for variables with three or more categories was completed with Chi square (Kruskal-Wallis $\mathrm{H}$ ). In all analyses, a p-value of 0.05 or less was considered statistically significant. Results were presented using tables, charts and texts as appropriate.

\subsection{Ethical Considerations}

Permission to carry out this study was sought and obtained from Research Ethics Committee, 68 Nigeria Army Reference Hospital Yaba (68NARHY). All participant subjects also gave an oral informed consent to be enrolled into the study. Also, to ensure the protection of the respondents' privacy, no identifying information like name, date of birth etc. was included in the questionnaire. Before and after data entry, all the recovered questionnaires were safely stored in a restricted area accessible only to the lead researcher.

\section{Results}

Out of the 390 questionnaires distributed for this study, 374 (95.9\%) were correctly filled and recovered and thus were included in this analysis.

Majority of the subjects were aged over 30 years (Mean \pm SD $=34.1 \pm 5.03$ ). Roughly three-fifth (61.5\%) were school certificate holders, 291 (77.8\%) were Christians whereas majority (81\%) were in active service. Out of these, $74.9 \%$ and $21.1 \%$ were trading/self-employed and civil/public servants and respectively. About four-fifth of the respondents' partners were aware of their HIV status (Table 1).

Regarding the knowledge of HIV, almost all of the respondents were aware that the virus can be transmitted from one person to another through vaginal sexual intercourse (97.9\%), blood and blood product transfusion (96.8\%), and sharing of unsterilized needles and sharp objects (93.3\%). Other means of the transmission correctly identified by greater proportion of the participants were through infected mother to unborn child (69.3\%), anal sexual intercourse as mentioned by 244 (65.2) respondents, breastfeeding (79.4\%) cum intravenous drug use and traditional circumcision which were recognised by 286 (76.5) and 301 $(80.5 \%)$ of the subjects respectively. Most of the women in this study were also aware that HIV is not contacted through the bite of mosquitoes (79.4\%), sharing of cups, plates and clothes with infected persons (90.6\%) or hugging someone who is HIV positive. Additionally, roughly nine out of every ten participants correctly mentioned that HIV is not contracted by shaking hands or and sitting close to/sharing same bed with an infected person. Lastly, kissing was also another means of transmission turned down by 274 (73.3\%) of the respondents (Table 2).

Concerning awareness of mother-to-child transmission of HIV, about threequarter (282) were aware that it can be transmitted to an unborn baby from the positive mother. Of these, 240 (85.1\%) were well-informed that increase mother's viral load can increase the chances of mother-to-child transmission whereas 
Table 1. Participants' socio-demographic attributes, $\mathrm{N}=374$.

\begin{tabular}{|c|c|c|c|c|}
\hline Variable & Categories & Freq. & Percent & $P$-value \\
\hline \multirow{3}{*}{ Age in years } & $21-29$ years & 82 & 21.9 & 0.926 \\
\hline & $30-39$ years & 227 & 60.7 & \\
\hline & 40 years and above & 65 & 17.4 & \\
\hline \multirow{4}{*}{ Educational status } & No formal education & 14 & 3.7 & 0.918 \\
\hline & Primary School & 37 & 9.9 & \\
\hline & Secondary School & 230 & 61.5 & \\
\hline & Post-Secondary School & 93 & 24.9 & \\
\hline \multirow{3}{*}{ Religion practiced } & Christian & 291 & 77.8 & 0.067 \\
\hline & Islam & 76 & 20.3 & \\
\hline & Pagan & 7 & 1.9 & \\
\hline \multirow{2}{*}{ Employment status } & Working & 303 & 81.0 & 0.178 \\
\hline & Not Working & 71 & 19.0 & \\
\hline \multirow{3}{*}{$\begin{array}{l}\text { Specific occupation } \\
\qquad \mathbf{N}=303\end{array}$} & Unspecified & 12 & 4.0 & NA \\
\hline & Civil/Public Servant & 64 & 21.1 & \\
\hline & Trading/Self employed & 227 & 74.9 & \\
\hline \multirow{5}{*}{ Ethnicity } & Igbo & 106 & 28.3 & 0.333 \\
\hline & Yoruba & 135 & 36.1 & \\
\hline & Hausa & 48 & 12.8 & \\
\hline & Other ethnic minorities & 83 & 22.2 & \\
\hline & Non-Nigerians & 2 & 0.5 & \\
\hline \multirow{2}{*}{$\begin{array}{l}\text { Husband/Partner aware of } \\
\text { participant's HIV status }\end{array}$} & No & 68 & 18.2 & 0.024 \\
\hline & Yes & 306 & 81.8 & \\
\hline
\end{tabular}

Mean $\pm \mathrm{SD}=34.1 \pm 5.03$ years; $\mathrm{SD}=$ Standard deviation

Table 2. Participants' knowledge of transmission of HIV, $\mathrm{N}=374$.

\begin{tabular}{lccc}
\hline & \multicolumn{3}{c}{ Responses } \\
\hline \multicolumn{1}{c}{ Beliefs on means of transmission of HIV } & Yes & No & I don't know \\
& $\mathbf{n}(\%)$ & $\mathbf{n}(\%)$ & n (\%) \\
\hline Vaginal sexual intercourse & $366(97.9)$ & $6(1.6)$ & $2(0.5)$ \\
Blood and blood product transfusion & $362(96.8)$ & $9(2.4)$ & $3(0.8)$ \\
Mosquito bites & $31(8.3)$ & $297(79.4)$ & $46(12.3)$ \\
Sharing of unsterilized needles and sharp objects & $351(93.9)$ & $8(2.1)$ & $15(4.0)$ \\
Sharing of cups, plates and clothes with infected persons & $14(3.7)$ & $339(90.6)$ & $21(5.6)$ \\
Sharing toilet with infected persons & $23(6.1)$ & $324(86.6)$ & $27(7.2)$ \\
Hugging an infected person & $16(4.3)$ & $346(92.5)$ & $12(3.2)$ \\
An infected mother to unborn child & $259(69.3)$ & $92(24.6)$ & $23(6.1)$ \\
Shaking hands with infected persons & $15(4.0)$ & $345(92.2)$ & $14(3.7)$ \\
Anal sexual intercourse & $244(65.2)$ & $40(10.7)$ & $90(24.1)$ \\
Kissing & $65(17.4)$ & $274(73.3)$ & $35(9.4)$ \\
Breastfeeding & $297(79.4)$ & $55(14.7)$ & $22(5.9)$ \\
Intravenous drug use & $286(76.5)$ & $56(15.0)$ & $32(8.6)$ \\
Traditional circumcision & $301(80.5)$ & $41(11.0)$ & $32(8.6)$ \\
Sitting close to/sharing same bed with an infected person & $13(3.5)$ & $349(93.3)$ & $12(3.2)$ \\
\hline
\end{tabular}


insufficient maternal multivitamin reserve was mentioned by 166 (58.9\%) of the subjects. Over ninety percent each of these women also correctly noted that the baby is not subjected to increased risk of maternal-to-child transmission of the virus if the mother hugs or shares the same bed with baby (Table 3 ).

Table 4 also shows the participants opinion regarding some of the preventive measures for MTCT. Of all the respondents, 215 (76.2\%) of those who believed

Table 3. Participants' Knowledge of PMTCT, $\mathrm{N}=374$.

\begin{tabular}{|c|c|c|c|}
\hline \multirow[b]{2}{*}{$\begin{array}{l}\text { Knowledge of maternal susceptibility in pregnancy and } \\
\text { potential for child transmission, } \mathrm{N}=374\end{array}$} & \multicolumn{3}{|c|}{ Responses } \\
\hline & $\begin{array}{c}\text { Yes } \\
\text { n }(\%)\end{array}$ & $\begin{array}{c}\text { No } \\
\text { n (\%) }\end{array}$ & $\begin{array}{l}\text { I don't know } \\
\text { n (\%) }\end{array}$ \\
\hline Can a pregnant woman be HIV positive? & $345(92.2)$ & $4(1.1)$ & $25(6.7)$ \\
\hline Can HIV be transmitted from an infected mother to child? & $282(75.4)$ & $64(17.1)$ & $28(7.5)$ \\
\hline \multicolumn{4}{|l|}{ Beliefs on factors promoting MTCT, N = 282} \\
\hline Increased mother's viral load & $240(85.1)$ & $17(6.0)$ & $25(8.9)$ \\
\hline Lack of multivitamins & $166(58.9)$ & $72(25.5)$ & $44(15.6)$ \\
\hline When mother is sick & $192(68.1)$ & $62(22.0)$ & $28(9.9)$ \\
\hline Mother having cracked nipples & $239(84.8)$ & $22(7.8)$ & $21(7.4)$ \\
\hline Premature baby & $90(31.9)$ & $114(40.4)$ & $78(27.7)$ \\
\hline Hugging the baby & $5(1.8)$ & $264(93.6)$ & $13(4.6)$ \\
\hline Sharing same bed with baby & $4(1.4)$ & $265(94.0)$ & $13(4.6)$ \\
\hline
\end{tabular}

Table 4. Participants' beliefs on means of prevention of MTCT.

\begin{tabular}{|c|c|c|c|}
\hline \multirow[b]{2}{*}{ Knowledge of preventive measures for MTCT, $\mathrm{N}=282$} & \multicolumn{3}{|c|}{ Responses } \\
\hline & $\begin{array}{l}\text { Yes } \\
\mathrm{n}(\%)\end{array}$ & $\begin{array}{c}\text { No } \\
\mathrm{n}(\%)\end{array}$ & $\begin{array}{l}\text { I don't know } \\
\text { n (\%) }\end{array}$ \\
\hline Pregnant woman eating balanced diet & $215(76.2)$ & $49(17.4)$ & $18(6.4)$ \\
\hline Caesarean section before the onset of labour & $219(77.7)$ & $30(11.6)$ & $33(11.7)$ \\
\hline Giving of antiretroviral drugs during and after pregnancy & $268(95.0)$ & $8(2.8)$ & $6(2.1)$ \\
\hline Use of breast milk substitute (powdered milk) & $254(90.1)$ & $15(5.3)$ & $13(4.6)$ \\
\hline Avoiding breast milk & $245(86.9)$ & $25(8.9)$ & $12(4.3)$ \\
\hline Use of directly expressed and boiled mother's breast milk & $48(17.0)$ & $127(45.0)$ & $107(37.9)$ \\
\hline $\begin{array}{l}\text { Breastfeeding baby by another mother who is not HIV } \\
\text { infected }\end{array}$ & $170(60.3)$ & $71(25.2)$ & $41(14.5)$ \\
\hline \multicolumn{4}{|l|}{$\begin{array}{l}\text { Awareness of the need to adopt PMTCT services } \\
\text { including, } N=374\end{array}$} \\
\hline Attending Antenatal clinic regularly & $365(97.6)$ & $1(0.3)$ & $8(2.1)$ \\
\hline $\begin{array}{l}\text { Ensuring that delivery is conducted by a skilled attendant } \\
\text { (Doctor or Midwife) }\end{array}$ & $359(96.0)$ & $4(1.1)$ & $11(2.9)$ \\
\hline $\begin{array}{l}\text { Attending } 6 \text { weeks postnatal clinic for proper assessment } \\
\text { and care }\end{array}$ & $358(95.7)$ & $4(1.1)$ & $12(3.2)$ \\
\hline Visiting family planning clinic 6 weeks after delivery & $259(69.3)$ & $67(17.9)$ & $48(12.8)$ \\
\hline
\end{tabular}


MTCT of HIV is possible agreed that consumption of balanced diet by pregnant mothers can reduce the chances, 268 (95\%) understood that giving of antiretroviral drugs during and after pregnancy can lower transmission risk, while 254 (90.1\%) saw the use of breast milk substitutes as another prevention strategy. Other measures agreed to were avoiding breast milk by $86.9 \%$ and surrogate caring mentioned by $60.3 \%$, among others. Nearly all our participants were aware that HIV-positive mothers should attend antenatal clinic regularly (97.6\%); that delivery of positive pregnant women must be conducted by a skilled doctor or midwife (96\%), as well as attend 6 weeks postnatal clinic for proper assessment and care. Nonetheless, just under $70 \%$ of the respondents stated that HIV-positive mothers should visit the family planning clinic 6 weeks after delivery for proper care.

Overall, 213 participants constituting 57\% of the women in this study accurately demonstrated good knowledge of MTCT and its prevention strategies (Figure 1).

Participants' PMTCT knowledge and its association with their sociodemographic variables.

According to Table 1, there was no significant association between the respondents' PMTCT knowledge and their age $[r=0.005, p=0.926]$, educational qualification $\left[\chi^{2}(3)=0.503, p=0.918\right]$, religion practiced $\left[\chi^{2}(2)=5.42, p=\right.$ $0.067]$, employment status $[Z=-1.35, p=0.178]$ and their ethnicity $\left[\chi^{2}(3)=\right.$ 3.405], $p=0.333$ ]. However, there was statistically significant association between the respondents' knowledge of PMTCT and their husbands'/partners' awareness of their HIV status $[Z=-2.261, p=0.024)$. Indeed, subjects whose spouse were aware demonstrated higher knowledge (mean $\left.\operatorname{rank}\left(\bar{X}_{R}\right)=193.44\right)$ compared to those whose spouse were not aware $\left(\bar{x}_{R}=160.79\right)$.

\section{Discussion}

Our study revealed that the disclosure rate $(81.8 \%)$ was high among our participants. This is comparable to $85 \%$ reported by Odiachi et al. in a mixed-methods

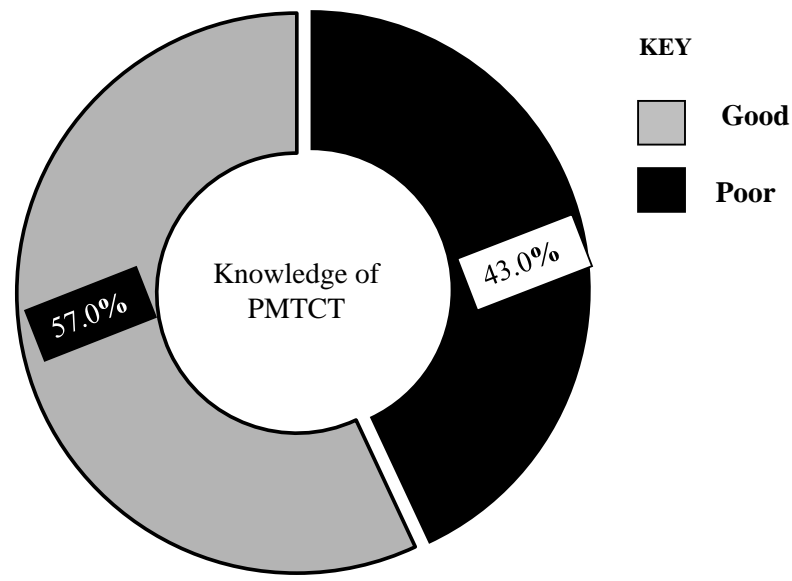

Figure 1. Doughnut chart showing overall knowledge of MTCT and its preventive measures, $\mathrm{N}=374$. 
study [19]. It is believed that HIV status disclosure can lower HIV spread occasioned by reduction in risky sexual behaviours [20]. Reduced number of sexual partners, regular condom use and lowering of casual sexual contacts have all been observed by Taiswa et al. to be among the direct positive outcomes of status disclosure [21]. Partner Notification Services (PNS) is among promising strategies being implemented to encourage status disclosure to partners. This has a potential of improving HIV testing services (HTS) uptake, and thus enhancing the achievement of UNAIDS target of $95 \%$ of HIV status awareness in any population. Improved targeted HIV testing and higher yield of case identification have been attributed to the use of PNS in many African settings [22] [23].

In addition, knowledge of both HIV transmission and MTCT was observed to be high among our participants. Such knowledge or awareness has a potential benefit of reducing MTCT if such translates to improvement in PMTCT services' seeking behaviour and its utilization by women living with HIV when they become pregnant. Ezenkiri et al. demonstrated a significant association between knowledge and positive attitude of expectant mothers to PMTCT in the northern part of Nigeria [24]. Such knowledge has been noted to be highly influenced by age, educational level, employment status, number of ANC follow-up visits for the ongoing pregnancy and parity in Ethiopia [25]. Although the relevance of these factors to knowledge of HIV transmission and MTCT is not the focus of the current study, it can be suggested that priority and enhanced PMTCT counselling should be offered to all HIV positive women who are within child bearing age.

Similarly, our respondents demonstrated high knowledge of PMTCT. This is significantly affected by disclosure of HIV status to partners, but did not appear to be influenced by either age, educational qualification, religion, employment status, or ethnicity. Further study may be necessary to elucidate the relationship between PMTCT knowledge and status disclosure. It is essential that information about PMTCT should be generously made available to all women of child bearing age, but more importantly, frequent reinforcement of such information to women living with HIV is a necessity in order to stem the current trend of HIV epidemic among children born in developing countries. Many of our respondents accepted surrogate caring as a replacement option for breastfeeding as well as the use of milk substitute to prevent MTCT. Widespread acceptability of surrogate caring in the context of conservative African culture may pose a challenge to its adoption and practice, and poor socioeconomic factor will make the option of milk substitute unaffordable for many families in Africa.

Furthermore, our participants acknowledged the need to adopt and access PMTCT services. Eliminating barriers that limit PMTCT uptake will improve access and promote utilization of the services by HIV positive pregnant women. It has been argued that strategies that improve antenatal care uptake can similarly facilitate implementation of effective PMTCT, and that creation of stigma-free environment and spousal support will mitigate certain socio-cultural barriers and enhance retention in PMTCT care [26]. Harrison et al. illustrated 
that male involvement and active participation in PMTCT may significantly improve its uptake and yield better outcome [27]. Besides, the impact of mentor mothers (MM) in improving the efficacy of PMTCT cannot be overemphasized. Use of MM has led to greater retention in care and improved viral load suppression in mothers, early presentation for EID in Nigeria and other similar African settings [28] [29] [30] [31]. MM support is also a key source of education, promotes exclusive breastfeeding, provides psychosocial support to patients and thereby reduces sense of alienation and serves as an interface between patients and healthcare providers, improving treatment adherence [32].

\section{Limitations of the Study}

A major limitation in this study is that of self-reporting whereby the respondents may give responses they think the researcher would be pleased to hear. Moreover, because this is self-sponsored study, we limited our data collection to one site alone and also included a limited number of respondents. Including larger sample size and more programmatic sites would have enriched the robustness of the study and improved on the external validity of these findings.

\section{Conclusion}

In conclusion, our study demonstrated a good knowledge of HIV transmission, MTCT and PMTCT among mothers who were receiving ART in our centre. Disclosure is a significant factor found to be associated with PMTCT knowledge. Translation of this knowledge to real practice of accessing PMTCT services needs further study. More studies can also explore if the observations in our study with mothers living with HIV will be comparable in similar population in different settings.

\section{Conflicts of Interest}

The authors declare no conflicts of interest regarding the publication of this paper.

\section{References}

[1] Joint United Nations Programme on HIV/AIDS and World Health Organization (2009) AIDS Epidemic Update. Joint United Nations Programme on HIV/AIDS, Geneva.

[2] The Working Group on Mother-To-Child Transmission of HIV (2005) Rates of Mother-to-Child Transmission of HIV-1 in Africa, America, and Europe: Results from 13 Perinatal Studies. Journal of Acquired Immune Deficiency Syndromes and Human Retrovirology, 8, 506-510.

[3] World Health Organization/United Nations Children's Fund and Joint United Nations Programme on HIV/AIDS (2011) A Guide on Indicators for Monitoring and Reporting on the Health Sector Response to HIV/AIDS. World Health Organization, Geneva.

[4] World Health Organization (2005) World Health Organization Call to Action: To- 
wards an HIV-Free and AIDS-Free Generation Prevention of 2005.

[5] Connor, E.M., Sperling, R.S., Gelber, R., Kiselev, P., Scott, G., Jo O’Sullivan, M., et al. (1994) Reduction of Maternal-Infant Transmission of Human Immunodeficiency Virus Type 1 with Zidovudine Treatment. New England Journal of Medicine, 331, 1173-1180. https://doi.org/10.1056/NEJM199411033311801

[6] World Health Organization (n.d.) Mother-to-Child Transmission of HIV. World Health Organization, Geneva.

[7] Joint United Nations Programme on HIV/AIDS (2018) Miles to Go: Global AIDS Update 2018.

[8] Joint United Nations Programme on HIV/AIDS (2017) Start Free Stay Free AIDS Free: 2017 Progress Report.

[9] Joint United Nations Programme on HIV/AIDS, President's Emergency Plan for AIDS Relief (PEPFAR) and Partners (2016) Start Free, Stay Free, AIDS Free: A Super-Fast Track Framework for Ending AIDS among Children, Adolescents and Young Women by 2020. Joint United Nations Programme on HIV/AIDS, Geneva.

[10] Tatagan, A., Mouhari-Toure, A., Saka, B., Akakpo, A.S., Kombate, D., Tchama, R., et al. (2011) Knowledge, Attitudes and Practices about Prevention of Mother to Child Transmission of HIV (PMTCT) among Pregnant Women in Antenatal Clinic at 2010 in Togo. Médecine Tropicale, 71, 472-476.

[11] Creek, T., Ntumy, R., Mazhani, L., Moore, J., Smith, M., Han, G., et al. (2009) Factors Associated with Low Early Uptake of a National Program to Prevent Mother to Child Transmission of HIV (PMTCT): Results of a Survey of Mothers and Providers, Botswana, 2003. AIDS and Behavior, 13, 356-364.

https://doi.org/10.1007/s10461-007-9322-8

[12] Olugbenga-Bello, A., Adebimpe, W.O., Osundina, F.F. and Abdulsalam, S.T. (2013) Perception on Prevention of Mother-to-Child-Transmission (PMTCT) of HIV among Women of Reproductive Age Group in Osogbo, Southwestern Nigeria. International Journal of Women's Health, 5, 399-405. https://doi.org/10.2147/IJWH.S45815

[13] Mkwanazi, N.B., Patel, D., Newell, M.-L., Rollins, N.C., Coutsoudis, A., Coovadia, H.M., et al. (2008) Rapid Testing May Not Improve Uptake of HIV Testing and Same Day Results in a Rural South African Community: A Cohort Study of 12,000 Women. PLoS ONE, 3, e3501. https://doi.org/10.1371/journal.pone.0003501

[14] Moses, A.E., Chama, C., Udo, S. and Omotora, B.A. (2009) Knowledge, Attitude and Practice of Ante-Natal Attendees toward Prevention of Mother to Child Transmission (PMTCT) of HIV Infection in a Tertiary Health Facility, Northeast-Nigeria. East African Journal of Public Health, 8, 128-135.

[15] Abajobir, A.A. and Zeleke, A.B. (2013) Knowledge, Attitude, Practice and Factors Associated with Prevention of Mother-to-Child Transmission of HIV/AIDS among Pregnant Mothers Attending Antenatal Clinic in Hawassa Referral Hospital, South Ethiopia. Journal of AIDS and Clinical Research, 4, Article No. 215. https://doi.org/10.4172/2155-6113.1000215

[16] Ogunbosi, B.O., Oladokun, R.E., Awolude, O., Brown, B., Adeshina, O., Kuti, M., et al. (2014) Missed Opportunities for Prevention of Mother-to-Child Transmission of HIV (PMTCT) in Ibadan, Southwest Nigeria. World Journal of AIDS, 4, 356-364. https://doi.org/10.4236/wja.2014.43042

[17] Hembah-Hilekaan, S.K., Swende, T.Z. and Bitto, T.T. (2012) Knowledge Attitudes and Barriers towards Prevention of Mother-to-Child Transmission of HIV among Women Attending Antenatal Clinics in Uyam District of Zaki-Biam in Benue State, 
Nigeria. African Journal of Reproductive Health, 16, 27-34.

[18] Nigerian Agency for AIDS Control (NACA) (2016) Fact Sheet: Prevention of Mother to Child Transmission (PMTCT), 2016. Nigerian Agency for AIDS Control, Abuja.

[19] Odiachi, A., Sam-Agudu, N.A., Erekaha, S., Isah, C., Ramadhani, H.O., Swomen, H.E., Charurat, M. and Cornelius, L.J. (2020) A Mixed-Methods Assessment of Disclosure of HIV Status among Expert Mothers Living with HIV in Rural Nigeria. PLoS ONE, 15, e0232423. https://doi.org/10.1371/journal.pone.0232423

[20] World Health Organization (2004) Gender Dimensions of HIV Status Disclosure to Sexual Partners: Rates, Barriers and Outcomes: A Review Paper. World Health Organization, Geneva.

[21] Taiswa, J., Mukhisa, E.L., Omolloh, R., Mochache, D., Nyacharo, J.A. and Masaba, B.B. (2020) Effects of Positive HIV Status Disclosure on Sexual Behaviour Change. International Journal of Nursing Education, 12, 292-295.

[22] Tih, P.M., Temgbait Chimoun, F., Mboh Khan, E., Nshom, E., Nambu, W., Shields, R., Wamuti, B.M., Golden, M.R. and Welty, T. (2019) Assisted HIV Partner Notification Services in Resource-Limited Settings: Experiences and Achievements from Cameroon. Journal of the International AIDS Society, 22, e25310. https://doi.org/10.1002/jia2.25310

[23] Mahachi, N., Muchedzi, A., Tafuma, T.A., Mawora, P., Kariuki, L., Semo, B.W, Bateganya, M.H., Nyagura, T., Ncube, G., Merrigan, M.B., Chabikuli, O.N. and Mpofu, M. (2019) Sustained High HIV Case-Finding through Index Testing and Partner Notification Services: Experiences from Three Provinces in Zimbabwe. Journal of the International AIDS Society, 22, e25321. https://doi.org/10.1002/jia2.25321

[24] Ezenkiri, J.N., Ezeani, U.B. and Okonkwo, I.M. (2020) Knowledge and Attitudes towards Preventive Measures of Mother-To-Child Transmission of HIV/AIDS among Expectant Mothers at the Federal Medical Centre, Katsina State, Nigeria. Journal of Medical Science and Clinical Research, 8, 128-135. https://doi.org/10.18535/jmscr/v8i9.25

[25] Abebe, A.M., Kassaw, M.W. and Shewangashaw, N.E. (2020) Level of Knowledge About Prevention of Mother-to-Child Transmission of HIV Option B+ and Associated Factors Among ANC Clients in Kombolcha Town, South Wollo Amhara Regional State, Ethiopia, 2017. HIVI AIDS-Research and Palliative Care, 12, 79-86. https://doi.org/10.2147/HIV.S242166

[26] Dirisu, O., Eluwa, G., Adams, E., Torpey, K., Shittu, O. and Adebajo, S. (2020) "I Think This Is the Only Challenge... the Stigma" Stakeholder Perceptions about Barriers to Antenatal Care (ANC) and Prevention of Mother-to-Child Transmission (PMTCT) Uptake in Kano State, Nigeria. PLoS ONE, 15, e0232028.

https://doi.org/10.1371/journal.pone.0232028

[27] Harrison, N.E., Oruka, K.E., Agbaim, U.C., Adegbite, O.A., Nwaiwu, O. and Okeji, N.A.E. (2020) Prevention of Maternal-to-Child Transmission of HIV: Knowledge, Attitude and Factors Influencing Active Participation among HIV-Positive Men in a Military Health Facility in Lagos, South Western Nigeria. Open Journal of Preventive Medicine, 10, 233-253. https://doi.org/10.4236/ojpm.2020.108017

[28] Sam-Agudu, N.A., Ramadhani, H.O., Isah, C., Anaba, U., Erekaha, S., Fan-Osuala, C., Galadanci, H. and Charurat, M. (2017) The Impact of Structured Mentor Mother Programs on 6-Month Postpartum Retention and Viral Suppression among HIV-Positive Women in Rural Nigeria: A Prospective Paired Cohort Study. Journal of Acquired Immune Deficiency Syndromes, 75, S173-S181. 
https://doi.org/10.1097/QAI.0000000000001346

[29] Igumbor, J.O., Ouma, J., Otwombe, K., Musenge, E., Anyanwu, F.C., Basera, T., Mbule, M., Scheepers, E. and Schmitz, K. (2019) Effect of a Mentor Mother Programme on Retention of Mother-Baby Pairs in HIV Care: A Secondary Analysis of Programme Data in Uganda. PLoS ONE, 14, e0223332.

https://doi.org/10.1371/journal.pone.0223332

[30] Sam-Agudu, N.A., Ramadhani, H.O., Isah, C., Erekaha, S., Fan-Osuala, C., Anaba, U., Adejuyigbe, E.A. and Charurat, M. (2017) The Impact of Structured Mentor Mother Programs on Presentation for Early Infant Diagnosis Testing in Rural North-Central Nigeria: A Prospective Paired Cohort Study. Journal of Acquired Immune Deficiency Syndromes, 75, S182-S189.

https://doi.org/10.1097/QAI.0000000000001345

[31] Fan-Osuala, C., Ramadhani, H., Erekaha, S., Anaba, U., Nwanne, G., Bathnna, M., Charurat, M. and Sam-Agudu, N. (2018) P-E2 The Impact of Structured Mentor Mother Support on Retention during the First 12 Months Postpartum among HIV Positive Women in Rural Nigeria. Journal of Acquired Immune Deficiency Syndromes, 77, 60. https://doi.org/10.1097/01.qai.0000532517.90716.7b

[32] Hamilton, A.R.L., le Roux, K.W.D.P., Young, C.W. and Sodergard, B. (2018) Mentor Mothers Zithulele: Exploring the Role of a Peer Mentorship Programme in Rural PMTCT Care in Zithulele, Eastern Cape, South Africa. Paediatrics and International Child Health, 40, 58-64. https://doi.org/10.1080/20469047.2018.1474697

\section{Questionnaire}

Dear Respondent,

This questionnaire is aimed at assessing the knowledge of HIV and its transmission from mother to child among HIV positive mothers in an Army Hospital in Lagos. You are going to be asked some questions and accepting to answer by checking the box below means you are willing to participate in the study. Please answer the questions as accurately as you can. All information provided will be handled confidentially. Your name is not required.

Agree [ ] Don't Agree [ ]
Thank you

\section{SECTION A: BIO-DATA}

1) Age in years as at last birthday:

2) Educational Status: None [ ] primary school [ ] secondary school [ ] post-secondary school [ ].

3) Religion: Christian [ ] Islam [ ] pagan [ ] others specify...........

4) Current work status a. working [ ] b. not working [ ].

5) Specify you job.

6) Your ethnicity? a. Igbo [ ] b. Yoruba [ ] c. Hausa [ ] d. others specify....

7) Does your spouse know about your HIV status? a. Yes [ ] b. No [ ].

SECTION B: KNOWLEDGE

8) HIV can be transmitted through: 


\begin{tabular}{|c|c|c|c|c|}
\hline & & Yes & No & Don't know \\
\hline $\mathrm{a}$ & Vaginal Sexual intercourse & & & \\
\hline $\mathrm{b}$ & Blood and blood product transfusion & & & \\
\hline c & Mosquito bites & & & \\
\hline $\mathrm{d}$ & Sharing of unsterilized needles and sharp objects & & & \\
\hline $\mathrm{e}$ & Sharing of cups, plates and clothes with infected persons & & & \\
\hline $\mathrm{f}$ & Sharing toilets with infected person & & & \\
\hline g & Hugging an infected person & & & \\
\hline h & An infected mother to unborn child & & & \\
\hline $\mathrm{i}$ & Shaking hands with infected persons & & & \\
\hline $\mathrm{j}$ & Anal sexual intercourse & & & \\
\hline $\mathrm{k}$ & Kissing & & & \\
\hline 1 & Breastfeeding & & & \\
\hline $\mathrm{m}$ & Intravenous drug use & & & \\
\hline $\mathrm{n}$ & Traditional circumcision & & & \\
\hline o & Sitting close to/ sharing same bed with an infected person & & & \\
\hline
\end{tabular}

9) Can a pregnant woman be HIV positive? Yes [ ] No [ ] Don't know [ ].

10) Can HIV be transmitted from an infected mother to a child? Yes [ ] No [ ] Don't know [ ].

11) If yes to question 10 when?

\begin{tabular}{cccc}
\hline & & Yes & No \\
\hline a & During pregnancy & & \\
b & During labour & \\
c & During Delivery & \\
d & During breastfeeding & \\
\hline
\end{tabular}

12) What do you think will encourage transmission of HIV from mother to child?

\begin{tabular}{cc}
\hline & \\
\hline a & Yes No Don't know \\
b & Lack of multivitamins \\
c & When mother is sick \\
d & Mother having cracked nipples \\
e & Premature baby \\
f & Hugging the baby \\
g & Sharing same bed with baby \\
\hline
\end{tabular}


13) Mother to child transmission of HIV can be prevented by?

Yes No Don't know

\begin{tabular}{ll}
\hline a & Pregnant woman eating balance diet \\
b & Caesarian section before the onset of labour \\
c & Giving of antiretroviral drugs to mother during and after pregnancy \\
d & Use of breast milk substitute (powdered milk) \\
e & Avoiding breastmilk \\
e & Use of directly expressed and boiled mother's breast milk \\
f & Breastfeeding bay by another mother who is not HIV infected \\
\hline
\end{tabular}

14) Are you aware that HIV infected pregnant woman should?

\begin{tabular}{|c|c|c|c|c|}
\hline & & Yes & No & Don't know \\
\hline a & Attend Antenatal clinic regularly & & & \\
\hline $\mathrm{b}$ & Be delivered by a skilled attendant (doctor or midwife & & & \\
\hline c & Visit postnatal clinic 6 weeks after delivery & & & \\
\hline $\mathrm{d}$ & Visit family planning clinic 6 weeks after delivery & & & \\
\hline
\end{tabular}

